\title{
Bioassay Procedure for the Diagnosis of Aflatoxicosis in a Pig Farm in Nsukka, South East Nigeria
}

\author{
S. V. O. Shoyinka' ${ }^{1}$, K. F. Chah ${ }^{1}$, C. P. Eze ${ }^{1}$, W. S. Ezema' ${ }^{1}$, I. R. Onoja ${ }^{1}$, P. U. Umeakuana ${ }^{2}$ \\ ${ }^{1}$ Department of Veterinary Pathology and Microbiology, University of Nigeria, Nsukka, Nigeria \\ ${ }^{2}$ Veterinary Teaching Hospital, University of Nigeria, Nsukka, Nigeria \\ Email: chekwube.eze@gmail.com
}

Received 12 June 2014; revised 30 June 2014; accepted 12 July 2014

Copyright (C) 2014 by authors and Scientific Research Publishing Inc.

This work is licensed under the Creative Commons Attribution International License (CC BY). http://creativecommons.org/licenses/by/4.0/

(c) (i) Open Access

\section{Abstract}

The owner of an intensively reared pig farm in Nsukka, South-East Nigeria reported the deaths (within one week) of 90 piglets (2-3 months of age) out of 150 piglets on the farm. The piglets were being fed home-compounded ration composed of spent grain (which appeared moldy) and other locally sourced materials. Clinical signs observed in affected piglets include sudden loss of appetite, diarrhea and distress grunting sound prior to death. Symptomatic treatment of the piglets which included the use of antibiotics (tetracycline, LA) did not appear to have ameliorated the condition. At necropsy carcasses were generally in fair to good body condition; with subcutaneous hemorrhages, mainly under the skin of head and neck regions. Lungs were congested and edematous, with froth along the tracheal and bronchial airways. The liver and spleen were moderately congested, while the mucosae of the gastrointestinal tract (which was free of ingesta) appeared mildly hyperaemic. No pathogenic bacterium was isolated from the heart blood and spleen. Histologic section of the liver showed centrilobular hepatocytes vacoulation and necrosis with hypertrophy of Kupffer cells that were in erythrophagocytosis. There was moderate fibrinous exudation into the interlobular septae. Spleen section showed severe erythrophagocytosis, but mild haemosiderosis. White pulp was either reactive or depopulated. Lungs were severely haemorrhagic with bronchitis and bronchiolitis. A tentative diagnosis of mycotoxicosis was made and the spent grain-compounded ration was fed to different groups of ducklings, with/without arginine and lysine supplementation. On the bases of clinical signs and mortality pattern; gross and histologic changes in the liver of the ducklings, a definitive diagnosis of aflatoxicosis was made. This paper emphasizes the experimental feeding of suspected feeds/feed ingredient to ducklings as a reliable diagnostic model for aflatoxicosis.

\section{Keywords}

Pigs, Spent Grain, Aflatoxicosis, Ducklings 


\section{Introduction}

Mycotoxins, the biochemical metabolites of fungi and contaminant of human and animal feed [1], are diverse naturally occurring toxins, known to elicit pathological consequences [2]-[4]. The effects of aflatoxins on farm animals have been reported with attendant down-regulation on production [5] [6]. In addition to being difficult to diagnose, the intoxication can be devastating, due to the fact that the suspect feed may have been consumed before the manifestation of clinical signs [7].

Mycotoxicosis may be broadly suspected in an outbreak because of varying number of chemically and structurally unrelated mycotoxins elaborated by mycotoxogenic fungi [6]. It is almost impossible to narrow down to the particular toxins precipitating the pathology [8].

The attendant economic impact of mycotoxicosis include: reduced productivity, decreased weight gain and feed efficiency, increased disease incidence consequent upon immunosuppression, devitalizing body organs and reproductive abnormality, morbidity and mortality [9]-[11].

Aspergillusflavus, A. parasiticus, and A. nomius, produce aflatoxin known as bisfuranocoumarin metabolites [7]-[11]. The fungi are capable of germinating at 15\% - 17\% moisture content, but infection and growth require higher moisture [5]. Aflatoxicosis was formally referred to as "X-disease" due to liver pathology described as "hepatitis X", around 1960 [7]. The toxins have affinity for liver where biotransformation occurs [7] and most animal exposure precipitate hepatopathy ranging from acute to chronic condition depending on toxin concentration, and nutritional status of the animals [12] [13]. Young animals are more susceptible than mature ones and toxic effects include: reduced rate of weight gain and feed conversion efficiency, toxic hepatitis, nephritis and hemorrhagic syndromes [4] [7] [12].

Aflatoxicosis has been severally and frequently reported in suckling piglets, growing and finishing pig and breeding stock [5] [11]. Although swine appears resistant to the concentration of $300 \mathrm{ppb}$, from time of weaning to marketing [11], Crenshaw [5] and Marin et al. [9] stated that low level of about 20 - $200 \mathrm{ppb}$ is capable of eliciting immunosuppression, and increase susceptibility to microbial infections. Long term accumulations of the metabolites predispose to cancer, hepatopathy, jaundice and internal hemorrhage [3] [4] [13]. High concentration of about 1000 - 5000 ppb was reported to precipitate acute condition and death [5]. The chemical analysis and immunoassay methods are more sensitive in detection of mycotoxins-(aflatoxin $\mathrm{B}_{1}$ at $3 \mathrm{ppb}$ ) in feed and even in liver [5] [7] [11]. Bioassay and demonstration of characteristic biological alterations as clinical signs and pathologic changes by means of duckling inoculation was done to strengthen the confirmatory diagnosis of Aflatoxicosis in this case.

\section{Case Report}

The owner of the pig farm, presented 6 dead piglets at the University of Nigeria Veterinary Teaching Hospital (UNVTH) on 03/06/2011 with case file No: 278/2008/94 and complained of piglet mortalities. The farm was visited by the ambulatory team of the UNVTH. The ingredients used by the owner to compound to the feed consisted of essentially moldy spent grains and other locally sourced materials like kitchen wastes and left over food from restaurants.

The owner indicated that he had lost 90 (60\%) out of 150 piglets aged 2 - 3 months and that the clinical signs observed in the pig farm included, loss of appetite, diarrhea and distress cry prior to death. The farm record stated that the flock was previously treated symptomatically with oxytetracycline $20 \%$, but there appeared to be no amelioration. At necropsy, the carcasses showed subcutaneous hemorrhage mainly under the skin of head and neck region. General body condition was fair to good. In addition to these observations the lungs were moderately congested and edematous, with froths along the tracheal and bronchial airways. The gastro intestinal tract contained no ingesta, but appeared mildly hyperemic in the piglets. No pathogenic bacteria were isolated from the samples collected from the heart and spleen. On the basis of the clinical signs, presence of moldy feed, postmortem lesions and bacteriology, mycotoxicosis (aflatoxicosis) was tentatively diagnosed. Tetracycline (20\%) was administered and the owner advised to suspend feeding the animal with the suspect feed. Feed samples as well as the samples of the spent grains were collected for biological assay.

\section{Bioassay Procedure for Aflatoxin Detection}

This was carried out following the procedure described by Newberne et al. (1966). Thirty six day old ducklings acquired from a local hatchery (at Ibagwa, Enugu State, Nigeria) were randomly divided into six groups (A, B, 
C, D, E and F) of 6 ducklings each. Group A ducklings were fed with commercial feed (vital ${ }^{\circledR}$ ) supplemented with arginine $(1.0 \% \mathrm{w} / \mathrm{w})$ and lysine $(0.8 \% \mathrm{w} / \mathrm{w})$ while groups $\mathrm{B}$ and $\mathrm{C}$ were fed with test (suspect) feed and spent grains respectively, both supplemented with arginine and lysine as in group A. Groups D, E and F were fed with unsupplemented commercial feed, test (suspect) and spent grain respectively. They were fed and given water adlibitum and observed for 21 days.

\section{Results}

The clinical signs observed in the ducklings in groups B, C and F were distress and vigorous wading in water shortly after feeding, depression followed by death whereas groups A, D and E showed no observable clinical signs. In groups B and C, 100\% and 50\% respectively of the ducklings died day 3 post feeding (PF), whereas 33.3\% died in group F at day 9 PF and no mortality was recorded in groups $\mathrm{A}, \mathrm{D}$ and $\mathrm{E}$. Post mortem findings in groups B, C and F included soiled vent which exuded watery feces on slight abdominal pressure, pale and enlarged liver (Figure 1), mid intestine filled with dark and clotted blood (Figure 2) while groups A, D and E presented no observable gross lesion except that round worms (Nematode) were recovered from the small intestines of group E at day 21 PF. Histologic section of the liver in both piglet and duckling (Figure 3 \& Figure 4) showed centrilobular hepatocytes vacoulation and necrosis.

\section{Discussion}

The morbidity and mortality pattern in the piglets presented acute course likely due to their age [4] [7] [12]. These may be due to overwhelming lethal concentration of the toxin in the feed and the precipitation of more toxic metabolite, epoxide of $\mathrm{AB}_{1}[7]$.

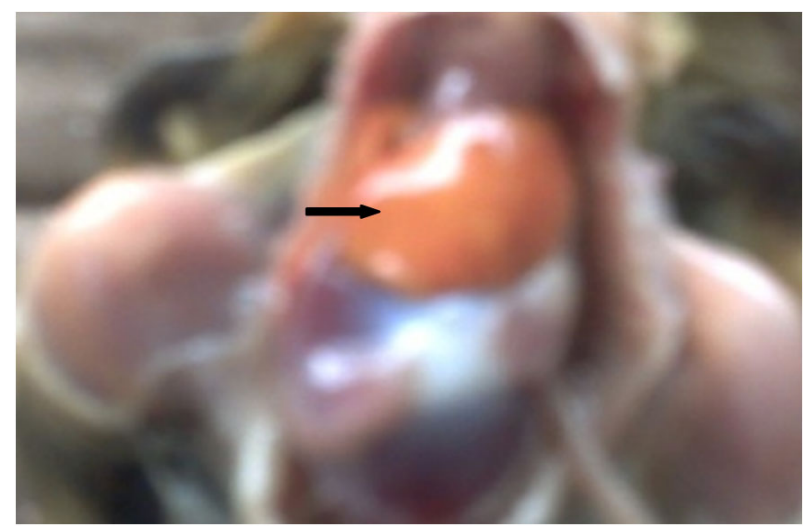

Figure 1. Liver of duckling showing paleness of the organ (arrow).

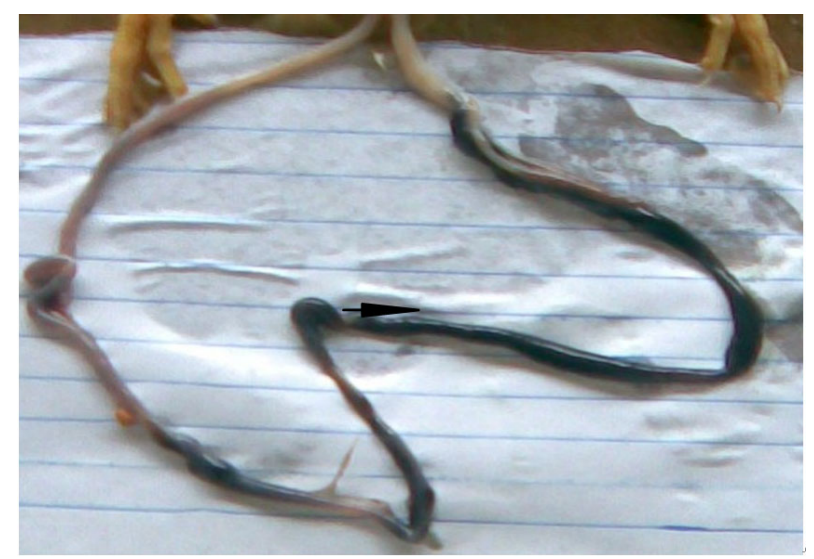

Figure 2. Intestine of duckling showing dark and clotted blood (arrow). 


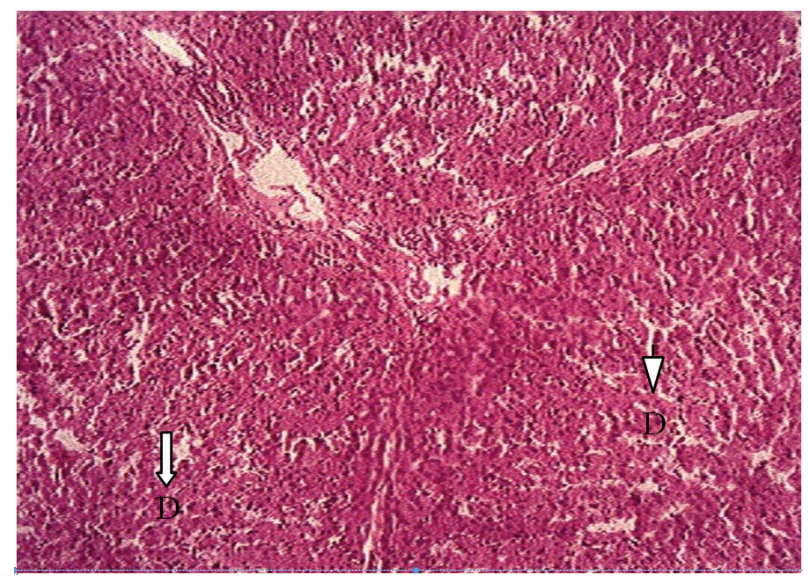

Figure 3. Liver section of piglet showing degeneration (D) of hepatocytes in the centrolobular area (arrows). H \& E. × 100.

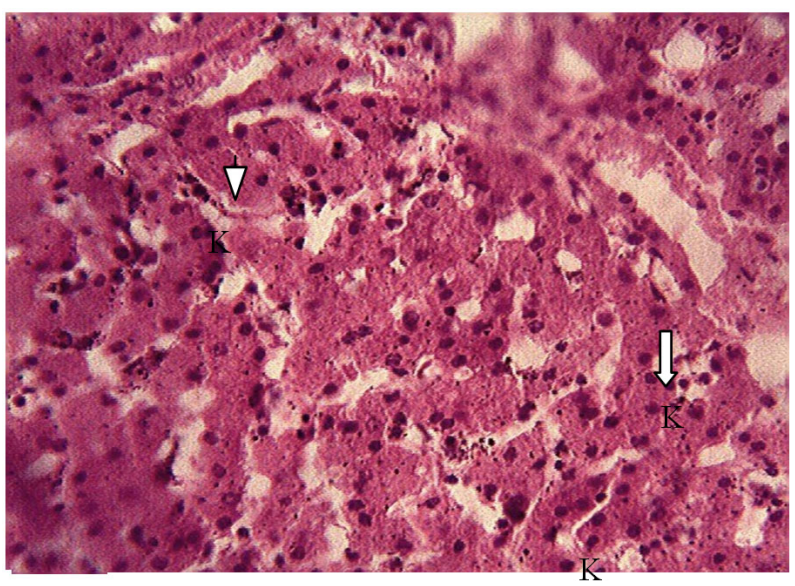

Figure 4. Liver section of piglet showing distortion of hepatic cord, degeneration and necrosis of hepatocytes and proliferation of kupffer cells (K) (arrows). H \& E. × 400.

The pigs were treated symptomatically with oxy-tetracycline L A, but there was no amelioration which was in line with the report by Harvey et al. [14]. However when the suspect feed was withdrawn, the mortality stopped underscoring the import of accurate diagnosis. The histopathological lesions observed in the piglets in this study were similar with the report of Okoye et al. [15] in broilers; with hypertrophy of Kupffer cells that were involved in erythrophagocytosis agreeing with earlier report by Kramer, [16]. Feeding a protein-deficient diet containing aflatoxin has been reported to result in more severe hepatic lesions especially when supplemented with arginine and lysine [17]. Spleen section showed severe erythrophagocytosis, but mild haemosiderosis likely due to age [18] and white pulps were either reactive or depopulated. There was moderate fibrinous exudation into the interlobular septae and the lung parenchyma were severely haemorrhagic with bronchitis or bronchiolitis [4] [7].

In groups B and C, the pattern of mortality was similar to the results obtained by Newberne et al. [19]. The clinical signs in these groups were related to the report of Gavin [7] in poults and ducklings which included: loss of appetite, nervous symptoms and in young birds, high and rapid mortality. Austwick [20], Bhat et al., [4]; Whitlow et al., [3] also stated that prolonged feeding of ducks with Aflatoxin contaminated feeds precipitate tumor more than in other birds. The toxin metabolites (epoxide of $\mathrm{AB}_{1}$ ) are said to bind with cellular components thus disrupting normal metabolism with pathologic consequences [7]. The diarrhea and hemorrhagic intestine indicated that the pathology of the disease may be entero-hepatic since the liver and intestine presented the gross lesions in both species except the skin and pulmonary lesions that were observed in the piglets. The morbidity and mortality (33.3\%) recorded in group F after 9 days may be associated with the unpalatability and 
amount of spent grain consumed by the ducklings. Gavin, [7], recommended the use of ducklings, tadpole larvae, salamander and brine shrimps for bioassay of aflatoxins. The round worms recovered from the small intestines of the test feed group at day 21 PF confirms that such feed compounding are usually associated with contaminations from various disease vectors like house flies.

\section{Conclusions}

Based on the clinical signs, gross and histologic lesions, and bioassay results, it is extremely likely that the feeds contained aflatoxin of lethal concentration since ducklings have been reported to show increased sensitivity to aflatoxin $\mathrm{B}_{1}$ diet slightly supplemented with arginine and lysine [7].

Even though chemical analysis and immunoassay methods are more sensitive in detection of mycotoxins(aflatoxin $\mathrm{B}_{1}$ at $3 \mathrm{ppb}$ ) in feed and even in liver, they are not sufficient proofs [7]. Bioassay and demonstration of characteristic biological alterations as clinical signs and pathologic changes by means of animal inoculation strengthen the confirmatory diagnosis of aflatoxicosis in animal [7] [19].

\section{References}

[1] Abramson, D. (2001) Mycotoxins in Swine Feed. Manitoba Feed Conference Alltech Inc., Nicholasville.

[2] D’Mello, J.P.F. (2000) Anti-Nutritional Factors and Mycotoxins. Farm Animal Metabolism and Nutrition, 383.

[3] Whitlow, L.W., Hagler, W.M. (JR) and Diaz, D.E. (2010) Mycotoxins in Feeds. Foodstuffs Magazine, 74, 74-84. http://fdsmagissues.feedstuffs.com/fds/Reference_issue_2010/13_Mycotoxins\%20in\%20Feeds.pdf

[4] Bhat, R., Ravishankar, V.R. and Karim, A.A. (2010) Mycotoxins in Food and Feed: Present Status and Future Concern. Comprehensive Reviews in Food Science and Food Safety, 9, 57-81.

[5] Crenshaw, M. (2008) Mycotoxin in Swine Diets.

[6] WHO (2011) Additional Studies on Aflatoxin and Health: Studies on Aflatoxin's Impact on Health.

[7] Gavin, L.M. (2003) Mycotoxin (Aflatoxin) in Clinical Veterinary Toxicology. In: Konnie, H.P., Ed., Mosby, Inc., 231-235.

[8] Swamy, H.V.L.N. (2009) Mycotoxin Mystery in Pigs: What Are the Causes? Alltech Inc., Nicholasville.

[9] Marin, D.E., Taranu, I., Bunaciu, R.P., Pascale, F., Tudor, D.S., Avram, N., Sarca, M., Cureu, I., Criste, R.D., Suta, V. and Oswald, I.P. (2002) Changes in Performance, Blood Parameters, Humoral and Cellular Immune Responses in Weanling Piglets Exposed to Low Doses of Aflatoxin. Journal of Animal Science, 80, 1250-1257.

[10] Murphy, J.M. and Kane, T.M. (2006) Thinking Globally, Acting Locally. Proceedings of the 6th London Swine Conference.

[11] Hannes, V (2008) Mycotoxins-Overview and Effects in Pigs. AFGRI Animal Feeds.

[12] Cullen, M.J. (2007) Hepatotoxic Agents: Liver, Biliary System, and Exocrine Pancreas. In: Pathologic Basis of Vetrinary Disease, McGavin, M. D. and Zachary, J.F., Eds., 4th Edition, Mosby Elsevier, Berlin, 445.

[13] Gelven, R. (2010) Approaches for Alleviating Toxic Effects of Aflatoxin in Lactating Dairy Cows and Weanling Pigs. A Thesis Presented to the Faculty of the Graduate School at the University of Missouri-Columbia, Columbia, 1-93.

[14] Harvey, R.B., Edrington, T.S., et al. (1995) Influence of Aflatoxin and Fumonisin B1 Containing Culture Material on Growing Barrows. American Journal of Veterinary Research, 56, 1668-1672.

[15] Okoye, J.O.A., Asuzu, I.U. and Gugnani, H.C. (1988) Paralysis and Lameness Associated with Aflatoxicosis in Broilers. Avian Pathology, 17, 731-734. http://dx.doi.org/10.1080/03079458808436490

[16] Kramer, J.W. (1969) Clinical Enzymology. In: Kaneko, J.J., Ed., Clinical Biochemistry of Domestic Animals, 4th Edition, Academic Press, San Diego,

[17] Madhavan, T.V. and Gopalan, C. (1965) Effect of Dietary Protein on Aflatoxin Liver Injury in Weanling Rats. Archives of Pathology, 80, 123.

[18] Ehrensperger, F. (2007) Pathology of the Spleen; Balgrade. Vetsuisse Faculty, Institute of Veterinary Pathology, 1-16.

[19] Newberne, P.M., Gerald, N.W. and Allen, III, H. (1966) Effects of Dietary Modifications on Response of the Duckling to Aflatoxin. The Journal of Nutrition, 90, 123-130.

[20] Austwick, P.K.C. (1978) Aflatoxicosis in Poultry: In: Wyllie, T.D. and Morehouse, L.G., Eds., Mycotoxic Fungi, Mycotoxins, Mycotoxicosis; an encyclopedic handbook, Vol. 2, Mycotoxicosis of Domestic and Laboratory Animals, Poultry and Aquatic Invertebrates and Vertebrates, Mercel Dekker, New York. 
Scientific Research Publishing (SCIRP) is one of the largest Open Access journal publishers. It is currently publishing more than 200 open access, online, peer-reviewed journals covering a wide range of academic disciplines. SCIRP serves the worldwide academic communities and contributes to the progress and application of science with its publication.

Other selected journals from SCIRP are listed as below. Submit your manuscript to us via either submit@scirp.org or Online Submission Portal.
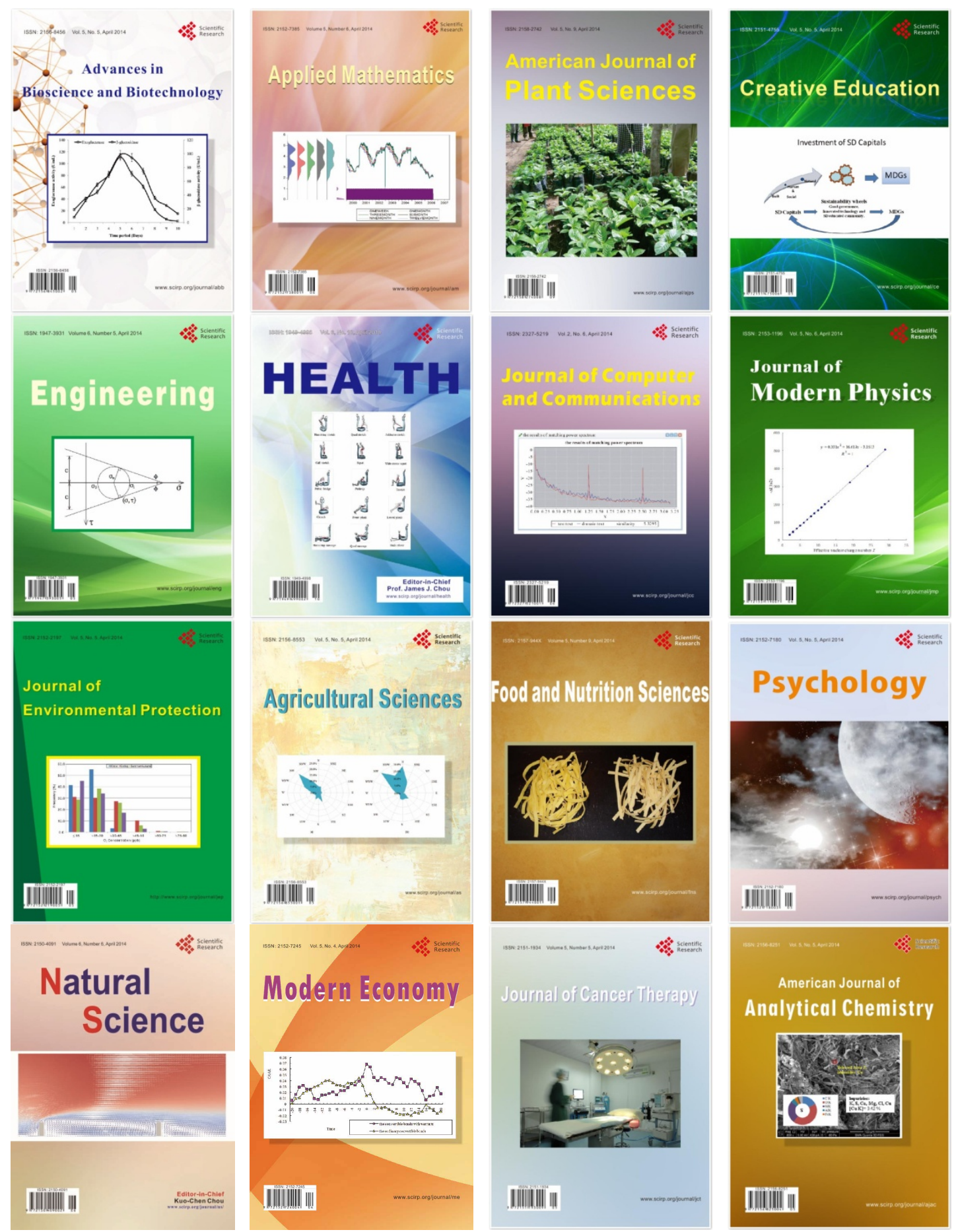